\title{
Impact of European Emergency Number (112) in out of hospital Cardiac Arrest: Trieste experience
}

Giuseppe Davide Caggegi ${ }^{1}$, Carlo Pegani ${ }^{1}$, Perla Rossini ${ }^{1}$, Michele Zuliani ${ }^{1}$, Erik Roman Pognuz ${ }^{1}$, Davide Durì ${ }^{2}$, Matteo Danielis ${ }^{3}$, Alberto Peratoner ${ }^{1}$

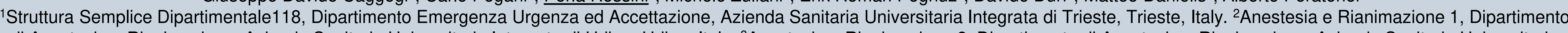

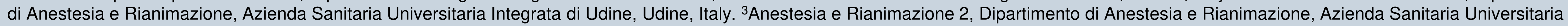
Integrata di Udine, Udine, Italy

\section{Purpose}

Accordingly to the EU's 2002 Health Regulatory Framework, the European Emergency Number 112 ("Numero Unico Europeo di Emergenza", NUE) has been instituted in Italy in 2006, but activated in the city of Trieste only since 4th April 2017. The adoption of the model of "Public Safety Answering Point" (PSAP), organized in a first general dispatch made by non-healthcare personnel and a second sanitary dispatch made by healthcare professional, added an obligatory step in the out of hospital survival chain that possibly caused changes in the response by prolonging time from the event to the emergency system activation (evaluated 90 seconds in mean as declared in the document "Servizio NUE 112 integrazioni al Disciplinare tecnico operativo Standard" drafted by the Italian Ministry of the Interior and published in January, 2018). Out-ofHospital Cardiac Arrest (OHCA) represents the first cause of death worldwide as well as one of the pathologies with a time-dependent outcome. Thus, the aim of the our study is to compare OHCA data between one year before and year after NUE-112 activation.

\section{Materials and Methods}

We analyzed data from OHCA collected in the Italian Registry for Cardiac Arrest ("Registro Italiano Arresti Cardiaci" - RIAC) database by the Emergency Medical Service (EMS) of Trieste between April 4th, 2016, to April 3rd, 2018. We divided the population into two groups: the preNUE group (A), in which OHCA occurs in the period between April $4^{\text {th }}, 2016$, to April $3^{\text {rd }}, 2017$, and the post-NUE group (B), in which OHCA occurs in the period between April $4^{\text {th }}, 2017$, to April $3^{\text {rd }}, 2018$.
We excluded cases of OHCA with no resuscitation attempts and which occurred in retirement home to reduce any bias. Data collected included (for each patient): age, sex, presence of witnesses, conduction of on-line CPR, execution of bystander CPR, time from dispatch to EMS arrival (considered adding 90 seconds in group B), type of presentation rhythm (FV/pulseless TV vs Asystole/PEA), time to CPR withdrawal, incidence of Return Of Spontaneus Circulation (ROSC). Chi-squared test was used to compare data. A P value of $<0.05$ was considered significant.

\section{Results}

Between Pre-112 (208 pt) (A) and Post-112 (206 pt) (B) group, mean age was 80 yo (69-87 (A), 68-88 (B), $\mathrm{p}=0,74)$; male sex was slightly predominant in both groups $(59,61 \%$ vs $55.34 \%$, $\mathrm{p}=0,48)$. Incidence of witnessed OHCA was similar $(67,78 \%$ vs $65,53 \%, p=0,67)$. On-line CPR improved after 112 institution $(16,34 \%$ vs $44,66 \%, \quad \mathrm{p}=<0,001)$ as the bystander CPR $21,15 \%$ vs $50,48 \%, \mathrm{P}=<0,001)$. Time from dispatch to EMS arrival was 10 minutes mean for both groups (7-13 vs 8-14, p=0,057); when adding to group (B) the time of call processing by the first general dispatch of NUE-112, a difference between the two groups appears (10 vs $11,5, \mathrm{p}<0.001)$. The presentation rythm was shockable in 33 cases (A) vs 30 (B) $(15.86 \%$ vs $14.56 \%, \mathrm{p}=0.78)$. Time to $\mathrm{CPR}$ withdrawal was 37 minutes (A, 27,5-50') vs 34 minutes (B, 24,5$\left.47^{\prime}, \mathrm{p}=0,03\right) .25$ attempts of resuscitations resulted in ROSC in both groups $(12,01 \%$ vs $12,13 \%, \mathrm{p}=1,0)$.

\section{Conclusions}

NUE-112 in Trieste brought a significant

improvement in on-line-CPR with higher

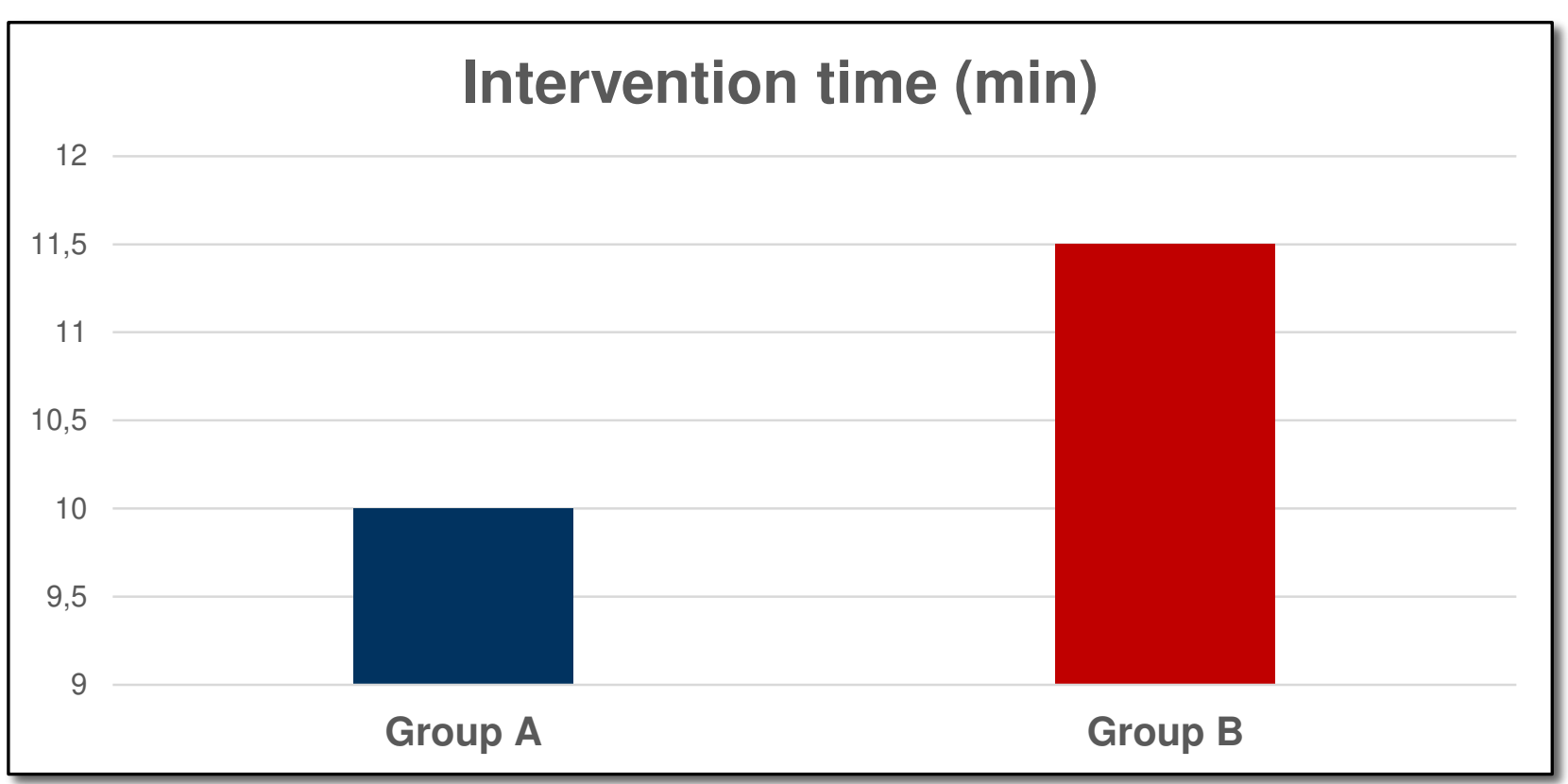

Fig. A: the increasing in intervention time in mean is significative in group B

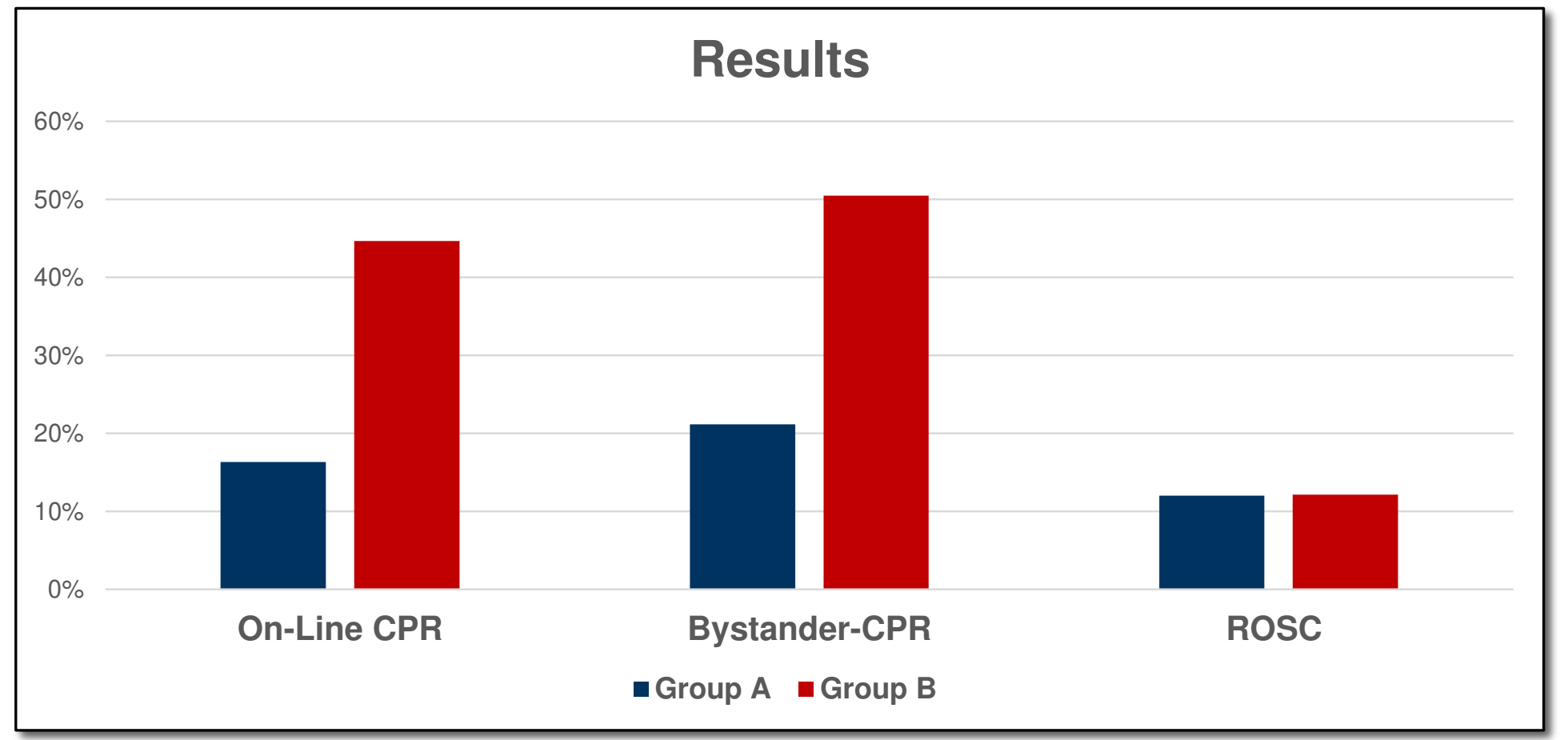

Fig. B: despite the increasing in On-line and Bystander CPR in group B, rate of ROSC remains unchanged incidence of bystander CPR, but also an increasing in intervention time by ALS. Nevertheless, rate of ROSC still remains similar. 